\title{
Stimulus-response durations in paired-associates learning
}

ALFRED A. BAUMEISTER, UNIVERSITY OF ALABAMA

WILLIAM F. HAWKINS, CENTRAL MICHIGAN UNIVERSITY

This study was conducted for the purpose of determining whether stimulus-response duration, independent of distribution of practice is related to learning of verbal paired associates. Both stimulis-response duration and inter-item interval were varied. It was concluded that stimulus-response time per se does slightly affect learning, but that distribution produces a more substantial effect.

Some recent studies of the temporal aspects of paired associate learning have indicated that rate of acquisition is related to exposure time of the paired stimulus and response terms (S-R duration) (Bugelski, 1962; Nodine, 1963; Nodine, 1965). On the other hand, total learning time appears to be unaffected by variations in $S-R$ exposure intervals. This suggests that explicit $S-R$ duration per se may not be relevant, but rather the important factor is the differential spacing of practice which has accompanied variations in S-R presentation time. Previous studies have confounded these two variables. In other words, a short $\mathrm{S}-\mathrm{R}$ duration may produce as rapid learning as a longer S-R presentation, provided Ss are given the same total time per item.

The present experiment was conducted for the purpose of determining whether explicit $\mathbf{S}-\mathbf{R}$ exposure duration, independent of total list time, influences rate of PA learning. The procedures reported by Bugelski (1962) were followed.

Method

The Hunter Card Master was used to present the paired-associates materials. Briefly, this apparatus consists of a visual display unit and a separate control mechanism. Stimuli are presented automatically on cards through a $3 \times 6$ in. window. A twin-shutter arrangement allows independent presentation of the left and right portions of the cards. All temporal aspects of the task can be controlled automatically. The stimulus materials consisted of the following eight pairs of nonsense syllables: GEY-NUR, KAR-WEH, BIH-XIR, CEZ-MUN, FAX-SOQ, TOF-LAH, DUP-TEZ, and GACQET. The first syllable of each pair was the stimulus term and the second, the response term. These materials are identical to those employedby Bugelski ( $1^{\prime}$;2).

Sixty undergraduate students, enrolled in Introductory Psychology, were randomly and equally assigned to five subgroups. All Ss learned the eight pairs to a criterion of two successive perfect recitations. The list was presented in three different orders to avoid
Table 1.

Summary of Experimental Design and Mean Trials to Criterion

\begin{tabular}{lccccc} 
Group S-Duration S-R Duration & $\begin{array}{c}\text { Inter-item } \\
\text { Interval } \\
\text { (sec.) }\end{array}$ & $\begin{array}{c}\text { Total Item } \\
\text { Time } \\
\text { (sec.) }\end{array}$ & $\begin{array}{c}\text { Mean Trials } \\
\text { to } \\
\text { Criterion }\end{array}$ \\
\hline I & 2 & 2 & 15 & 19 & 12.2 \\
II & 2 & 7 & 10 & 19 & 10.9 \\
III & 2 & 15 & 2 & 19 & 9.2 \\
IV & 2 & 2 & 2 & 6 & 17.6 \\
V & 2 & 7 & 2 & 11 & 11.1 \\
\hline
\end{tabular}

serial effects. There was no intertrial rest period.

The stimulus item was exposed for $2 \mathrm{sec}$. during which time $\mathrm{S}$ was instructed to anticipate the response term. The S-R exposure duration and the interitem interval were different for each group. Table 1 presents the various temporal arrangements. Groups III, IV, and $\mathrm{V}$ represent essentially a replication of Bugelski's conditions.

\section{Resulis and Discussion}

The criterion measure consisted of the number of trials required to learn all eight pairs to two successive anticipations. Means are presented in Table 1. The standard deviations ranged from 4.1 to 6.1.

Analysis of variance of these data yielded $F=5.4$ $(p<.05)$. An inspection of Table 1 reveals that a short S-R duration is not associated with particularly poor performance, provided total item time is beyond some minimal value. This effect is most clearly seen in comparison of Groups I, III, and IV. Rehearsing appears to occur about equally well whether or not the pair is physically present. It can be concluded that total item time is more crucial, within the limits explored here, than explicit S-R presentation per se. This statement, however, must be qualified to the extent that there was a tendency for item duration, independent of total item time, to be related to performance. Group III tended to perform slightly better than Group $I(p<.10)$. The requirements placed on a short-term memory trace would appear to be greater in the situation where the item exposure time is short.

\section{References}

Bugelski, B. R. Presentation time, total time, and mediation in paired-associate learning. J. exp. Psychol., 1962, 63, 409-412.

Nodine, C. F. Stimulus durations and stimulus characteristics in paired-associates learning. J. exp. Psychol., 1963, 66, 100106.

Nodine, C. F. Stimulus durations and total learning time in paired associates learning. J. exp. Psychol., 1965, 69, 534-536. 